\title{
Damping of Power System Oscillation using STATCOM Integrated with SMES
}

\author{
Amol M. Raut \\ M. Tech, (IPS) \\ G H Raisoni College of Engg \\ Nagpur
}

\author{
K. D. Joshi \\ Research Scholar \& Associate \\ Professor \\ G H Raisoni College of Engg \\ Nagpur
}

\author{
V. K. Chandrakar \\ Professor \\ G H Raisoni College of Engg \\ Nagpur
}

\begin{abstract}
STATCOM is a FACTS device, which is shunt connected to power system. It operates as a voltage source converter. It has many application like Voltage stability, damping of oscillation, power flow control etc. SMES is an energy storage system which can be applied to large power system. In this paper impact of STATCOM integrated with a SMES on two machine power system is explored.
\end{abstract}

\section{Keywords}

Voltage Source Converter (VSC), STATCOM (Static Synchronous Compensator), SMES (Superconducting Magnetic Energy Storage), FACTS (Flexible AC Transmission System)

\section{INTRODUCTION}

STATCOM is a FACTS device; shunt connected to system by means of power electronics to control power and transient stability on transmission system. The STATCOM regulates voltage by controlling reactive power absorbed from or injected into the power system.

STATCOM is traditionally used for controlling bus voltage and influencing power flow. The DC side of STATCOM gives an opportunity to introduce energy storage. This has been expanded by A. R. Arsoy et al. in [2]. Capability of SMES as an effective energy storage is described in [7], [8], [12]. Optimal location of SMES for improvement of voltage stability is described in [11]. Many author have explored STATCOM plus SMES combination for addressing various power system issues [3], [4], [5]. In this paper, a phasor model of STATCOM is suitably modified to demonstrate the influence of an SMES. Fig. 1 shows the schematic of interfacing an SMES with STATCOM.

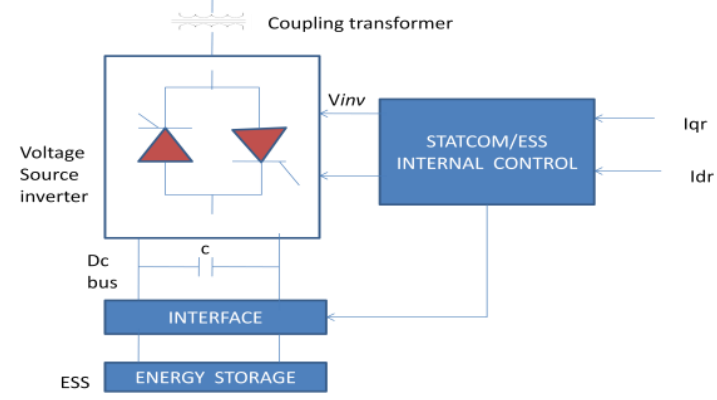

Fig.1. Block diagram of STATCOM + SMES

In this paper, the effectiveness of SMES on power system stability has been examined on a reasonably big power system.

\section{TEST SYSTEM}

Test system consist of generator of $1000 \mathrm{MW}$ connected to a load center through a tie line of $700 \mathrm{~km}$ length, $500 \mathrm{kv}$ rating. The applied load is $5000 \mathrm{MW}$ resistive load. The load is also connected to $5000 \mathrm{MW}$ generating station. The system supplied $950 \mathrm{MW}$ to transmission line which is near to surge impedance loading of $966 \mathrm{MW}$. Fig. 2 represents a two machine transmission system with fault at Bus3 [14].

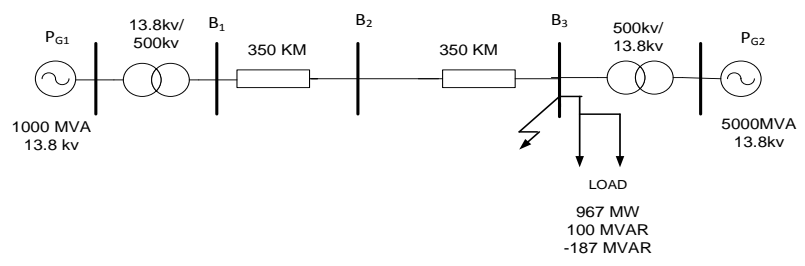

Fig. 2. Two machine transmission system

The STATCOM is located at bus1. The phasor model of STATCOM has been used as given in MATLAB simulink. The internal control scheme is reproduced below. [6]

Fig.3 Shows STATCOM control circuit. Positive sequence component of primary voltage is synchronous with PLL. The PLL is used to compute the $\mathrm{d}$ and $\mathrm{q}$ components of the AC three-phase voltage and currents.

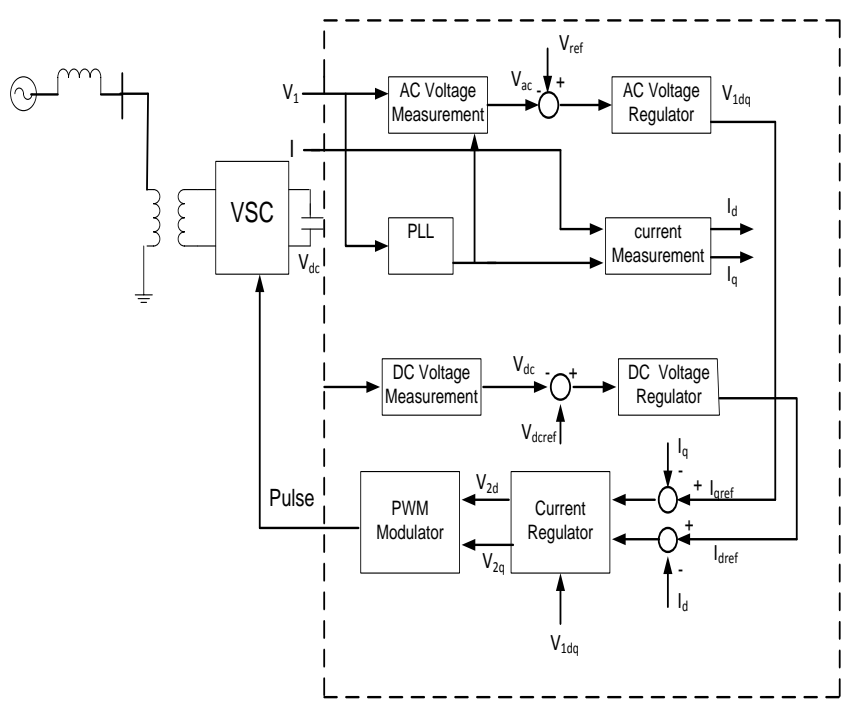

Fig. 3 Control circuit for STATCOM [6] 
Control circuit consists of outer loop and inner loop. An outer loop contained of an AC voltage regulator and a DC voltage regulator. The AC voltage regulator gives the Iqref, the DC voltage regulator gives Idref for current regulator. An inner current loop contains a current regulator. The current regulator, regulates the PWM converter gives magnitude and phase of voltage. The current regulator forecast the voltage output from the voltage measurement $\left(\mathrm{V}_{l d}, \mathrm{~V}_{1 \mathrm{q}}\right)$ and the transformer leakage reactance.

\section{ENERGY STORAGE SYSTEM}

Flywheel, Battery storage, Compressed air, super conducing magnetic energy storage, Thermal, Hydrogen, Pumped water etc are the different energy storage system available. SMES has high efficiency, high power density, and responds at fast pace to power system disturbance, therefore, SMES is a potential solution for dealing with power imbalance in a power system, enhancing stability and improving power quality. [8], [9], [11].

An advantage of SMES is that it can charge and discharge at a rapid rate as compared to battery. It has no moving parts and there are no power losses in SMES. SMES is highly sensitive to temperature. A coil should be at an very low temperature so that it work as a superconductor. In this case SMES consist of $100 \mathrm{MJ}$ coil, having $96 \mathrm{MW}$ power rating and $24 \mathrm{kv}$ voltage is used.

\section{INTEGRATION OF STATCOM AND SMES}

In order to integrate SMES with STATCOM, a DC-DC converter is required. So as to optimised the sizing of SMES The relationship between is shown in following fig. and described by equation,

$$
\text { Vsmes }_{-a v}=(1-2 d) V d c_{-} a v
$$

Where-

Vsmes_av-Average voltage of SMES coil $\mathrm{V} d c$-Average dc voltage of DC-DC chopper d- Duty cycle

At a duty cycle of 0.5 , there is no energy transfer, the average SMES coil voltage is equal to zero and the SMES coil current is constant. Equation implies that charging and discharging of coil depend on value of $d$. Below 0.5 , coil is in charging condition and vice versa. The simulation model is based on above equation.

\section{TEST SYSTEM WITH STATCOM AND SMES}

Fig.4 shows MATLAB simulink model of two-area system. The three-phase to ground fault is occurred at load centre. The STATCOM+SMES is located at generator end.

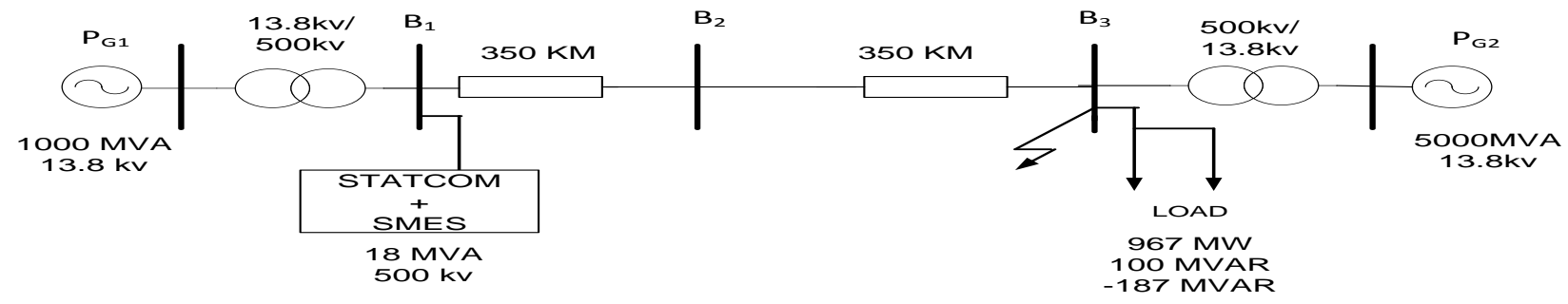

Fig.4:-Schematic model of Two machine system with STATCOM and SMES

Control system block diagram is shown below as given in [3].

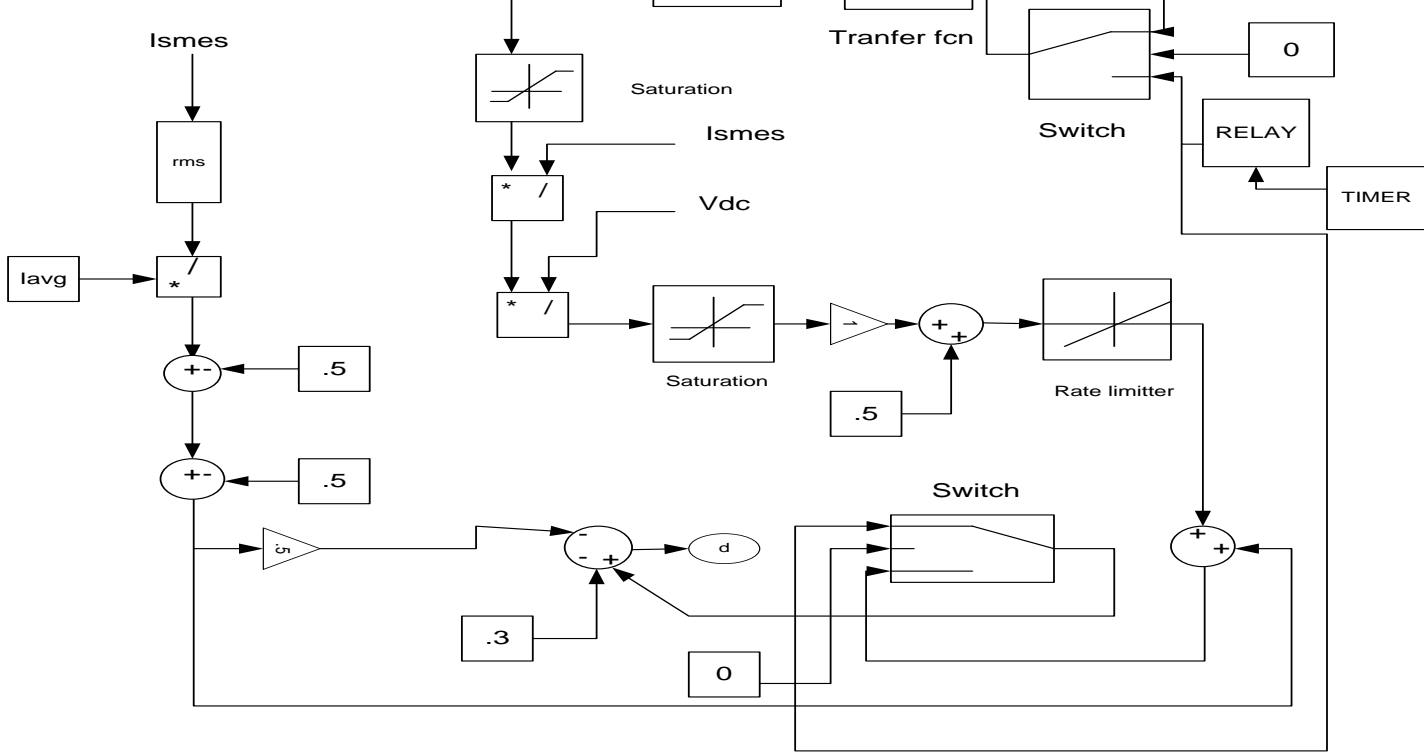

Fig.5 Control circuit of SMES [2] 
To assess the impact of SMES on this system a three phase to ground fault was created at Bus 3 for duration of fault of 0.21 second. The results for various conditions are shown below.

\section{SIMULATION AND RESULT}

Our Fig.6 shows response of reactive power with respect to voltage of a STATCOM. As soon as voltage of STATCOM is decreases, reactive power of STATCOM increases as shown in fig.6
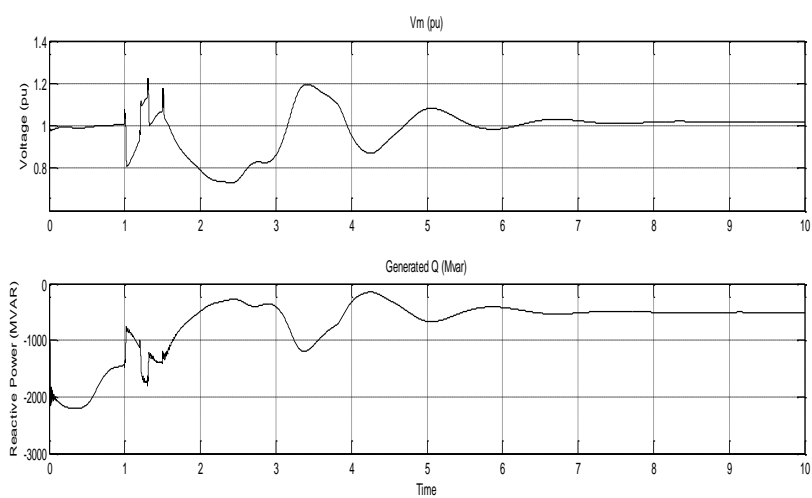

Fig. 6 Reactive Power of STATCOM

Fig.7 shows impact of STATCOM, STATCOM+SMES on active power flow between bus 1 and bus3. Settling time of waveform is improved with STATCOM+SMES.As seen in fig 7, with active power support from SMES the power oscillations following a fault die out immediately.

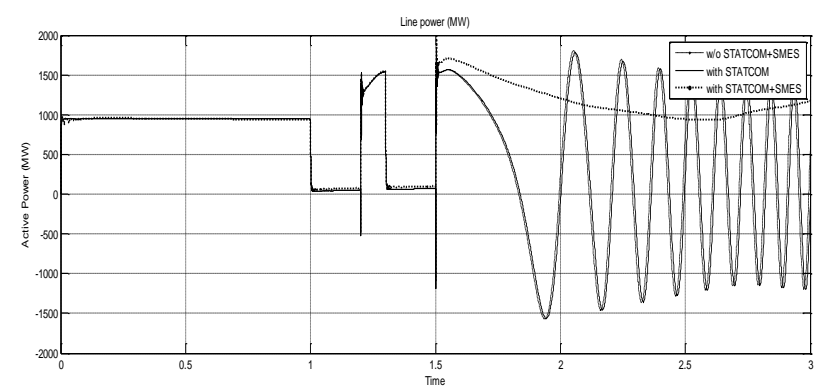

Fig. 7 Active Power from Bus1 To Bus3

One more interesting observation pertains to improvement in critical clearing time. When a fault of 0.21 seconds was applied, the system with only STATCOM was found to be unstable, however the system involving STATCOM-SMES returns to stability, thus providing a higher stability margin. This fact is evident from the following figure which shows rotor angle difference of the two machine system.

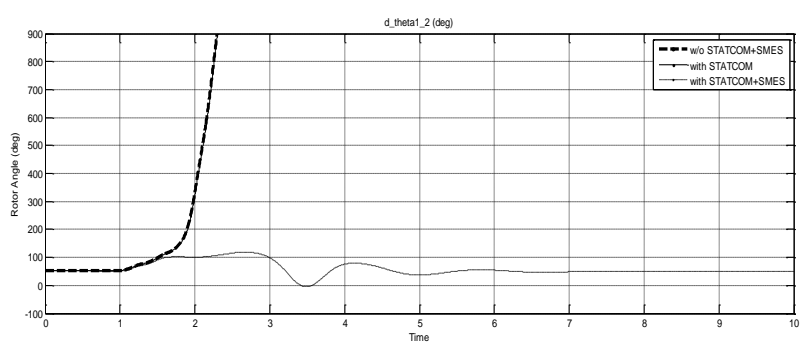

Fig.8 Rotor angle of machine
The variation near to fault is as shown in fig.9. It is observed that system is unstable with STATCOM, but it get stable by integrating SMES with STATCOM.

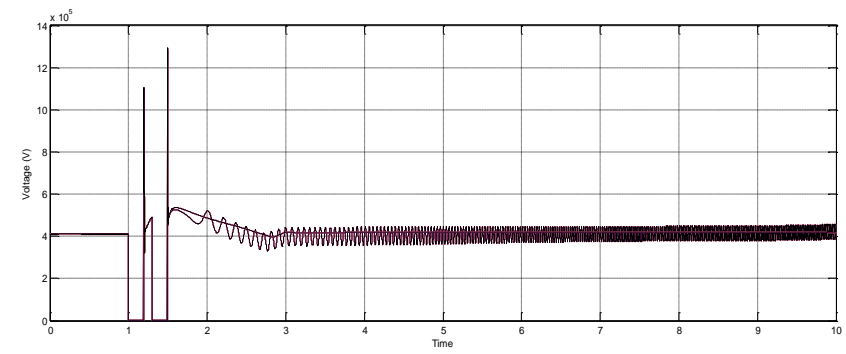

Fig.9 Voltage variation near to the fault

Active power supply by SMES to power system is as shown in fig. 10

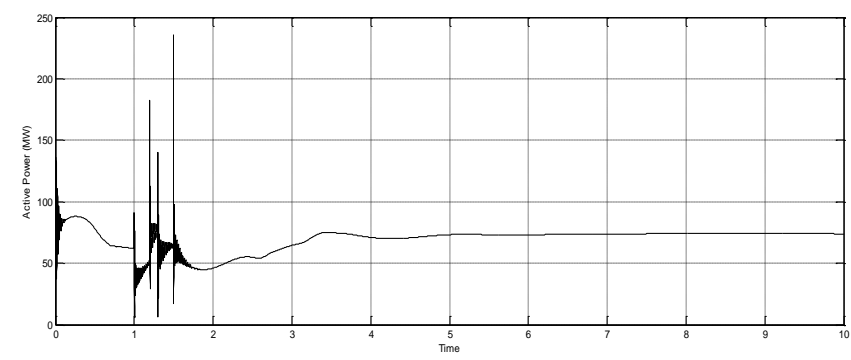

Fig. 10 Active power of SMES coil

\section{CONCLUSION}

This paper has described the integration of STATCOM with SMES. It is found that the real power support from SMES during fault condition helps in maintaining system stability. Power oscillations damp out considerably faster as compared to a system with only STATCOM. It was found that the critical clearing time has also improved significantly by introduction of SMES, thus providing more margins for stability. In order to observed detailed simulation for other frequency ranges, a detailed model will be required which may be explored in future. Further the impact of STATCOM+SMES can be explored in a larger panel system in future, involving more number of power system components.

\section{REFERENCES}

[1] M. Klein, G. J. Roger, S. Moorty, P. Kundur. "Analytical Investigation of Factors Influencing Power System Stabilizer Performance", IEEE Trans. On Energy Conversion, vol. 7, No. 3, September 1992.

[2] Arsoy, Y. Liu, S. Chen, Z. Yang, M. Crow, P. Ribeiro, "Dynamic Performance of a Static Synchronous Compensator with Energy Storage", IEEE Trans. On Power system, 2001

[3] M. Anju, R. Rajasekaran," Co-ordination Of Smes With Statcom For Mitigating SSR And Damping Power System Oscillations In A Series Compensated Wind Power System", ICCCI-2013

[4] A. B. Arsoy, Y. L Iu, P. F. Ribeiro, \& F. Wang, "STATCOM SMES", IEEE Industry application magzine Mar/Apr, 2003 
[5] M. Beza, M. Bongiorno, "An Adaptive Power Oscillation Damping Controller by STATCOM With Energy Storage", IEEE Trans.on Power Systems, 2014

[6] N. G. Hingorani, L. Gyugui, "Understanding the FACTS: concept and technology of flexible AC transmission system", wiley (India) IEEE press 2011.

[7] J. Fang, J. Wen, S. Wang, J. Shi, L. Ren, Y. Tang, X. Peng, and Z. Chen, "Laboratory and Field Tests of movable conduction-Cooled High-Temperature SMES for Power System Stability Enhancement", IEEE trans. On applied sc, vol. 23 no. 4, august 2013

[8] W. Hassenzahl, "Superconducting magnetic energy storage," IEEE Trans. Magn., vol. MAG-25, no. 2, pp. 750-758, Mar. 1989

[9] M. Reddy, M. Kavitha, “ Facts Controllers Implementation In Energy Storage Systems For Advanced Power electronics applications - A Solution", AJSCS, Issue 2, Vol. 1 January 2010.
[10] A. Taguchi, T. Imayoshi, T. Nagafuchi, T. Akine, N.Yamada, and H. Hayashi," A Study of SMES Control logic for power System stabilization" , IEEE Trans Applied sc vol. 17, no. 2, june 2007.

[11] X. Huang, G. Zhang, and L. Xiao, "Optimal Location of SMES for Improving Power System Voltage Stability", IEEE trans applied sc vol. 20, no. 3, june 2010

[12] F. Trillaud and L S Cruz, "Conceptual Design of a 200kJ 2G-HTS Solenoidal $\mu$-SMES”, IEEE Trans On Applied Sc, Vol.24 2014

[13] L. Sabrine, H. Othman, "Wind Generator Stability by Using STATCOM", The fifth International Renewable energy congress IREC March 2014

[14] D. Jovcic, G.N.Pillai "Analytical Modeling of TCSC Dynamics" IEEE Trans. on Power Delivery, vol 20, Issue 2, April 2005 